\title{
Decreased Proliferation, Interleukin 2 Synthesis, and Interleukin 2 Receptor Expression Are Accompanied by Decreased mRNA Expression in Phytohemagglutinin-stimulated Cells from Elderly Donors
}

\author{
James E. Nagel, Rajesh K. Chopra, Francis J. Chrest, Michael T. McCoy, * Edward L. Schneider, * \\ Nikki J. Holbrook, * and William H. Adler \\ Clinical Immunology Section and *the Laboratory of Molecular Genetics, Gerontology Research Center, National Institutes on Aging, \\ National Institutes of Health, Baltimore, Maryland 21224
}

\begin{abstract}
Using cDNA probes to human interleukin 2 (IL2) and interleukin 2 receptor (IL2R), the amount of IL2 and IL2R mRNA produced by PHA stimulated peripheral blood mononuclear cells from young ( $<40 \mathrm{yr}$ ) and old ( $>60 \mathrm{yr}$ ) donors was quantitated. Stimulated cell cultures from each individual were also examined for proliferative ability, expression of membrane IL2R, membrane IL2R density, and for the amount of IL2R shed into the culture supernatant. Induction of IL2 and IL2R mRNAs were decreased in cells from elderly individuals, as were the levels of IL2 secretion, the percentage of IL2R+ T cells and the density of membrane IL2R per cell. The results suggest that decreased expression of both IL2 and IL2R mRNA contributes to the low synthesis of IL2 and membrane IL2R, respectively, and is partially responsible for the diminished proliferative activity observed in lymphocytes from the elderly.
\end{abstract}

\section{Introduction}

Antigen and mitogen activate T cells to secrete IL2 and express membrane IL2R (1). T cell proliferation, although dependent upon the interaction of cells and the activation stimulus (2), is actually initiated by signals generated after the binding of IL2 with its membrane receptor (IL2R) ${ }^{1}$ (3). Therefore, any defect in the production or secretion of IL2, or in the expression of membrane IL2R can contribute to a low proliferative response. Furthermore, recent studies have shown that activated T cells shed IL2R into the cell culture supernatant (4) and that this soluble IL2R is capable, under specific experimental conditions, of binding IL2 $(5,6)$. While there is no clear evidence that soluble IL2R have a physiologic role, they may function to downregulate IL2 driven immunoproliferation.

Previous studies have demonstrated that IL 2 secretion by $T$ lymphocytes of both experimental animals and humans decreases with age (for review see references 7 and 8). Although reconstitution of in vitro cell mediated immunity by exoge-

Address reprint requests to Dr. Nagel, Clinical Immunology Section, Gerontology Research Center, 4940 Eastern Avenue, Baltimore, MD 21224.

Received for publication 11 March 1987 and in revised form 22 October 1987.

1. Abbreviations used in this paper: CTLL, cytotoxic T cell line.

J. Clin. Invest.

(c) The American Society for Clinical Investigation, Inc.

0021-9738/88/04/1096/07 \$2.00

Volume 81, April 1988, 1096-1102 nous IL2 has been reported (9), most studies demonstrate that exogenous IL2 is incapable of fully restoring the low proliferative response of cells from aged animals or elderly humans (10-12). This suggests that along with less IL2 secretion by cells from old donors, there may be a defect in membrane IL2R expression as well. Since the synthesis of IL 2 and IL2R is regulated at the level of mRNA $(13,14)$, the present study utilized cDNA probes to examine IL2 and IL2R mRNA expression. We present evidence of decreased mRNA accumulation for IL2 and IL2R in PHA-stimulated cells from old individuals. The results also show decreases in the synthesis of IL2R in general, as well as in the percentage of IL2R positive cells and the membrane IL2R density per cell. There was also a slightly greater loss of membrane-associated IL2R by PHA-activated PBL from old individuals.

\section{Methods}

Separation of PBL. Fresh heparinized blood was obtained from healthy laboratory personnel less than $40 \mathrm{yr}$ of age $(n=13$; age $=28.7 \pm 1.4 \mathrm{yr} ;$ mean $\pm \mathrm{SEM})$ and volunteers of over $60 \mathrm{yr}$ of age $(n$ $=17$; age $=74.4 \pm 1.9 \mathrm{yr}$ ) participating in Baltimore Longitudinal Study on Aging (BLSA). The criteria of selection of healthy volunteers has been described previously (15). The blood was diluted twofold in RPMI 1640 containing 2\% fetal bovine serum (FBS) (Hazleton Research Products, Lexena, KS), and centrifuged at $400 \mathrm{~g}$ for $30 \mathrm{~min}$ over Ficoll-sodium diatrizoate (LSM; Litton Bionetics, Kensington, MD). Cells from the interface were collected and washed three times in culture medium. The resulting PBL were suspended in complete culture medium, which consisted of RPMI 1640 (Gibco Laboratories, Grand Island, NY), 10\% FBS, and $100 \mu \mathrm{g} / \mathrm{ml}$ gentamycin.

Proliferation assay. PBL $\left(10^{5} /\right.$ well) were cultured in triplicate in 96-well flat-bottomed microculture plates (Costar, Cambridge, MA) in a total volume of $0.2 \mathrm{ml}$. The cultures were stimulated with PHA (PHA-P; Wellcome Reagents Ltd., Beckenham, UK) at a final concentration of $0.5 \mu \mathrm{g} / \mathrm{ml}$. The cultures were incubated at $37^{\circ} \mathrm{C}$ for $72 \mathrm{~h}$ in a humidified atmosphere with $5 \% \mathrm{CO}_{2}$ in air. Cell proliferation was quantitated by $\left[{ }^{3} \mathrm{H}\right]$ thymidine $(1 \mu \mathrm{Ci} /$ well, $2 \mathrm{Ci} / \mathrm{mmol}$ sp act, New England Nuclear, Boston, MA) incorporation during the last $18 \mathrm{~h}$ of culture. The cells were harvested onto glass fiber filters, washed in succession with water and methanol, and air-dried before the addition of scintillation fluid and subsequent analysis by scintillation counting.

IL2 assay. Supernatants for IL2 determination were collected after 24-72 $\mathrm{h}$ in culture. IL2 was assayed by determining the ability of the culture supernatant to stimulate $\left[{ }^{3} \mathrm{H}\right]$ thymidine incorporation by IL2dependent cytotoxic $T$ cell line (CTLL)-2 cells (16). For this bioassay, $100 \mu \mathrm{l}$ of the culture supernatant was twofold serially diluted in complete culture medium supplemented with $5 \times 10^{-5} \mathrm{M} 2$-mercaptoethanol. 5,000 CTLL in a volume of $100 \mu \mathrm{l}$ were added to each well and the plates were incubated at $37^{\circ} \mathrm{C}$ for $24 \mathrm{~h}$. For the last $4 \mathrm{~h}$ of culture, 1 $\mu \mathrm{Ci}$ of $\left[{ }^{3} \mathrm{H}\right]$ thymidine was added to each well and thymidine incorporation into DNA was measured. Partially purified laboratory standard IL2 was titrated in each experiment to provide a standard curve. In 
selected experiments recombinant IL2 (Genzyme, Boston, MA) and BRMP Reference Reagent Human IL2 (Jurkat) (Biological Response Modifiers Program, National Cancer Institute, Frederick Cancer Research Facility, Frederick, MD) were also used as standards. The units of IL2 were based on and expressed as BRMP units.

Flow cytometric analysis of IL2 receptors. The expression of membrane IL2R on PBL was examined with a fluorescein conjugated anti-IL2R monoclonal antibody (Becton Dickinson Co., Mountain View, CA). The culture conditions were the same as described for the proliferation assay. After $72 \mathrm{~h}$ of stimulation, cells from three microtiter wells were pooled, washed, and then stained with the FITC conjugated anti-IL2R antibody and propidium iodide (PI) as described previously $(17,18)$. Cell preparations were analyzed on a flow cytometer with an integrated computer (Ortho Cytofluorograf $50 \mathrm{H}$ with a 2150 Data Handling System; Ortho Diagnostics, Westwood, MA). Histograms were generated from live cells as determined by forward scatter and fluorescein fluorescence. Only viable cells (i.e., those not stained by PI) were analyzed for IL2R expression.

Soluble IL2R assay. PBL $\left(5 \times 10^{5}\right)$ were cultured in $1 \mathrm{ml}$ of complete medium in $75 \times 100 \mathrm{~mm}$ plastic tubes in a $5 \% \mathrm{CO}_{2}$ and humidified environment. After $72 \mathrm{~h}$, tubes were vortexed and then centrifuged. Supernatants were saved for soluble IL2R assessment. The cell pellet was washed three times in PBS, pH 7.2, and then dissolved in 1 $\mathrm{ml}$ of $1 \%$ Triton X-100 (Sigma Chemical Co., St. Louis, MO). All test samples were stored at $-70^{\circ} \mathrm{C}$ until assayed for IL2R. A commercial ELISA kit was used according to the manufacturer's instructions. IL2R concentrations are expressed in units per milliliter. $1,000 \mathrm{U}$ is defined by the manufacturer as the amount of soluble IL2R in $1 \mathrm{ml}$ of a standard reference preparation of supernatant from PHA-stimulated PBL (T Cell Sciences, Cambridge, MA).

Preparation and analysis of $m R N A$. PBL were cultured in $75-\mathrm{cm}^{2}$ flasks at a density of $10^{6}$ cells $/ \mathrm{ml}$. After 6 and $14 \mathrm{~h}$ of stimulation, cells were collected by centrifugation and washed with ice-cold PBS, pH 7.4. Total cellular RNA was extracted in $4 \mathrm{M}$ guanidinium isothiocyanate and pelleted through a cesium chloride cushion (19). For Northern blot analysis 10-20 $\mu \mathrm{g} /$ lane of total RNA, denatured by heating to $65^{\circ} \mathrm{C}$ in $50 \%$ formamide, was electrophoresed on a formaldehyde gel (1\%) as described by Thomas (20) and transferred to a membrane (Gene Screen Plus; DuPont/New England Nuclear, Boston, MA). Plasmids containing cDNAs encoding the human IL2R (provided by Dr. Warren C. Leonard, National Cancer Institute, Bethesda, MD) (21), human IL2 (22), and human actin (provided by Dr. Laurence $\mathrm{H}$. Kedes, Stanford University School of Medicine, Palo Alto, CA) (23) genes were labeled to a high specific activity with $\left[{ }^{32} \mathrm{P}\right] \mathrm{CTP}$ using the random primer method (24). The membrane was hybridized with the probes at $42^{\circ} \mathrm{C}$ for $24 \mathrm{~h}$ in a mixture containing $50 \%$ formamide, $1 \%$ SDS, $1 \mathrm{M}$ sodium chloride, $10 \%$ dextran sulfate, and $100 \mu \mathrm{g} / \mathrm{ml}$ salmon sperm DNA. After hybridization, the blots were washed at room temperature for $5 \mathrm{~min}$ in $2 \times \mathrm{SSC}(1 \times \mathrm{SSC}$ is $0.15 \mathrm{M} \mathrm{NaCl}, 0.015 \mathrm{M}$ sodium citrate, $\mathrm{pH} 7.2$ ) followed by a second wash at $60^{\circ} \mathrm{C}$ for $30 \mathrm{~min}$ in $2 \times$ SSC $-1.0 \%$ SDS, and by a third wash at room temperature in $0.1 \times$ SSC. Air-dried filters were exposed at $-70^{\circ} \mathrm{C}$ to Kodak XAR film (Eastman Kodak, Rochester, NY) with intensifying screens. Quantitative analysis of autoradiograms from Northern blot analysis was performed using a scanning densitometer with the results presented as arbitrary units corresponding to the relative areas under the peaks.

Data analysis and statistics. The significance of the difference between group means was analyzed by the $t$ test for unpaired samples. $P$ values $<0.05$ were taken as statistically significant.

\section{Results}

Proliferative ability and IL2 secretion. As shown in Table I, the $\left[{ }^{3} \mathrm{H}\right]$ thymidine incorporation into DNA of PHA stimulated PBL was significantly lower in cells from old donors. To ascertain that this alteration in proliferative ability was not accounted for by alterations in the representation of the $\mathrm{T}$ cell
Table I. Effect of Age on PHA-induced Cell Proliferation and IL2 Synthesis by Cells from Young and Old Donors

\begin{tabular}{cccc}
\hline & Young & Old & Significance* \\
\hline $\begin{array}{c}\text { Proliferation } \\
(\mathrm{cpm})\end{array}$ & $136,200 \pm 9,761$ & $72,450 \pm 8,129$ & $P<0.001$ \\
IL2 $(\mathrm{U} / \mathrm{ml})$ & $14.9 \pm 2.7$ & $8.3 \pm 1.9$ & $P<0.05$ \\
\hline
\end{tabular}

Data for proliferation are $\left[{ }^{3} \mathrm{H}\right]$ thymidine incorporation in counts per minute (mean \pm SEM, $n=13$ for young and 17 for old).

IL2 activity was calculated by probit analysis and is expressed in BRMP Reference Standard Human IL2 (Jurkat) units.

* $t$ test.

subpopulations, the $T$ cell subsets of each individual in the study were examined with monoclonal antibodies specific for T cells (OKT3, CD3), helper/inducer T cells (OKT4, CD4), cytotoxic/suppressor T cells (OKT8, CD8), and the SRBC receptor (OKT11, CD2) (Ortho Diagnostics, Raritan, NJ). As shown in Table II, there was no statistically significant difference between the young and elderly groups for $\mathrm{CD} 3, \mathrm{CD} 8$, or CD2 phenotypes. Among the individuals studied, the elderly group had a slightly $(P<0.05)$ increased representation of $\mathrm{CD}^{+}$cells. IL2 production of the PHA-stimulated cultures was bioassayed using an IL2-dependent cloned cytotoxic $\mathrm{T}$ cell line (CTLL-2). Although there was considerable variation among the individuals in each group, elderly subjects produced approximately one-half the amount of IL2 as the young donors (Table I).

Cell membrane IL2R expression. The documented inability of exogenous IL2 to consistently and fully correct the low proliferative capacity of cells from old donors suggests that in addition to low IL2 secretion there are other defects present. To test one possibility, cultures of PHA-stimulated cells from young and old donors were washed, stained with an FITC-labeled anti-IL2R monoclonal antibody and examined for cell membrane IL2R expression by flow cytometry. This was routinely done after 72 h of PHA stimulation since preliminary experiments, as well as previous reports (25), demonstrated maximal expression of membrane IL2R at this time. Stimulated cells from old donors demonstrated a significantly $(P<0.001)$ lower percentage of IL2R positive cells $(50.6 \pm 3.0 \%$; mean \pm SEM) when compared with cells from the

Table II. Effect of Age on T Cell Subsets Determined by Monoclonal Antibodies

\begin{tabular}{lccc}
\hline & \multicolumn{3}{c}{ Percent positive cells } \\
\cline { 2 - 4 } & Young & Old & Significance \\
\hline OKT3 (CD3) & $64.3 \pm 2.5^{*}$ & $63.9 \pm 3.5$ & $\mathrm{NS}^{\ddagger}$ \\
OKT4 (CD4) & $41.4 \pm 2.5$ & $49.8 \pm 3.0$ & $P<0.05$ \\
OKT8 (CD8) & $23.4 \pm 2.0$ & $19.5 \pm 3.0$ & $\mathrm{NS}$ \\
OKT11 (CD2) & $78.0 \pm 1.7$ & $78.8 \pm 3.1$ & $\mathrm{NS}$ \\
& & & \\
\hline
\end{tabular}

* Percentage of positive cells within the peripheral lymphocyte population determined by single color flow cytometry.

Mean \pm SEM, $n=13$ for young and 15 for old.

${ }^{\ddagger}$ test. 


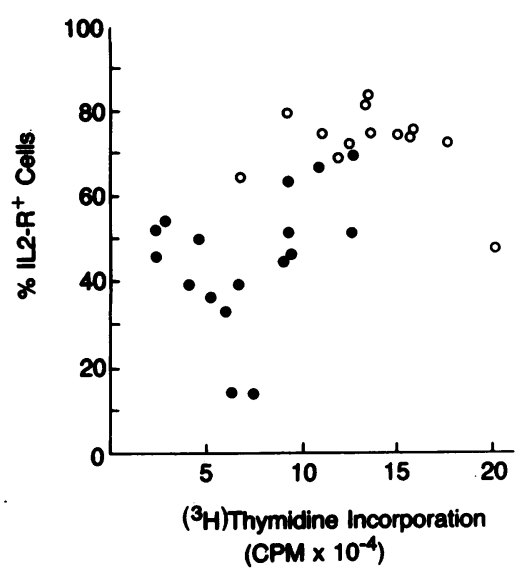

analyzed. Proliferative ability was quantified by $\left[{ }^{3} \mathrm{H}\right]$ thymidine incorporation into cellular DNA of 72-h PHA stimulated cultures. (•) Cells from old donors, (O) cells from young donors.

young donors $(73.1 \pm 2.7 \%)$. The lower percentage of stained IL2R positive cells in the cultures from the old donors corresponded with the low proliferative response of these cells (Fig. 1). There was less concordance between IL2 produced by the cells and IL2R expression. Despite large variations in IL2 production the IL2R expression segregated into two groups. Most young individuals $(9 / 12)$ produced $>5,000 \mathrm{U} / \mathrm{ml}$ of IL2R, whereas only $2 / 15$ elderly donors synthesized this amount of IL2R (Fig. 2). As shown in Fig. 3, there was considerable overlap among individuals in the young and old groups in the amount of both IL2 and IL2R produced. There was certainly no trend toward the greatest defects being found in the oldest individuals and raises the question of a survivor effect in these persons. In Fig. 4 representative histograms of the fluorescence distribution of IL2R on 72-h PHA-activated cells from four young and four old donors are shown. When the pattern of the fluorescence intensity was examined, it was apparent that the stimulated cells from the young and aged donors displayed major differences in the amount of fluorescence as well as the percentage of stained cells. Since the number of cells analyzed was constant $(10,000)$ and the electronic gain for fluorescence was standardized, this difference in fluorescence intensity was quantitated by arbitrarily dividing the histogram at channel

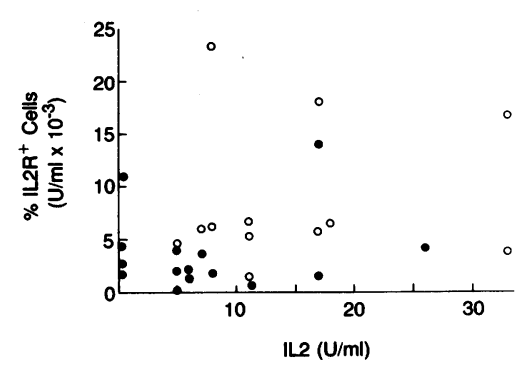

Figure 2. Relationship of IL2R to IL2 synthesis. IL2 was assayed by determining the ability of supernatants from PHA stimulated cell cultures to augment the uptake of $\left[{ }^{3} \mathrm{H}\right]-$ thymidine by an IL2 dependent cell line (CTLL-2). Units of IL2

were calculated by probit analysis and expressed in BRMP Reference Standard Units. IL2R was determined using a commercial ELISA assay and are expressed in units per milliliter. IL2R represents the sum of the soluble and membrane bound levels for each individual. (0) represent cells from young ( $<40 \mathrm{yr}$ old) and ( $\bullet$ ) elderly ( $>60 \mathrm{yr}$ old) subjects.

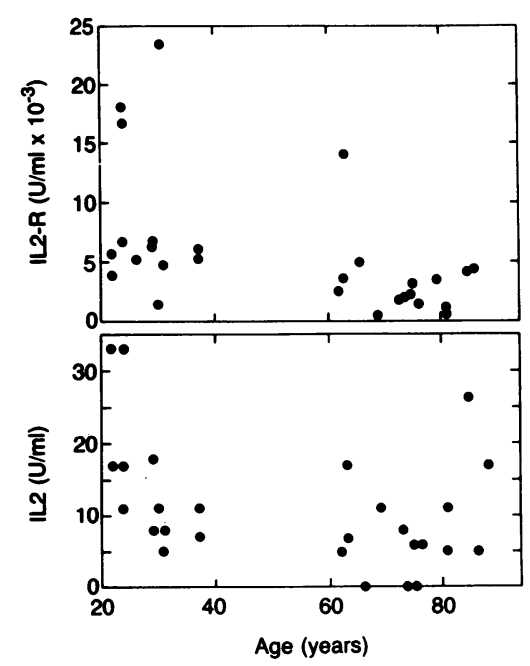

Figure 3. Comparison of IL2 (bottom) and IL2R (top) units to age of donor. IL2 was assayed by determining the ability of supernatants from PHA-stimulated cell cultures to augment the uptake of $\left[{ }^{3} \mathrm{H}\right]$ thymidine by an IL2 dependent cell line (CTLL-2). Units of IL2 were calculated by probit analysis and expressed in BRMP Reference Standard Units. IL2R was determined using a commercial ELISA assay and are expressed in units per

milliliter. IL2R represents the sum of the soluble and membrane bound levels for each individual.

100 and determining the percentage of cells in both the high $(>100)$ and low $(<100)$ regions. Stained cells from young subjects showed a pattern of distribution in which $59.8 \pm 3.9 \%$ (mean \pm SEM) of the cells were present in channels above number 100 , while the stained preparation of cells from elderly donors only had $38.7 \pm 3.0 \%$ of the cells present in the same area. This difference is statistically significant $(P<0.001)$ and

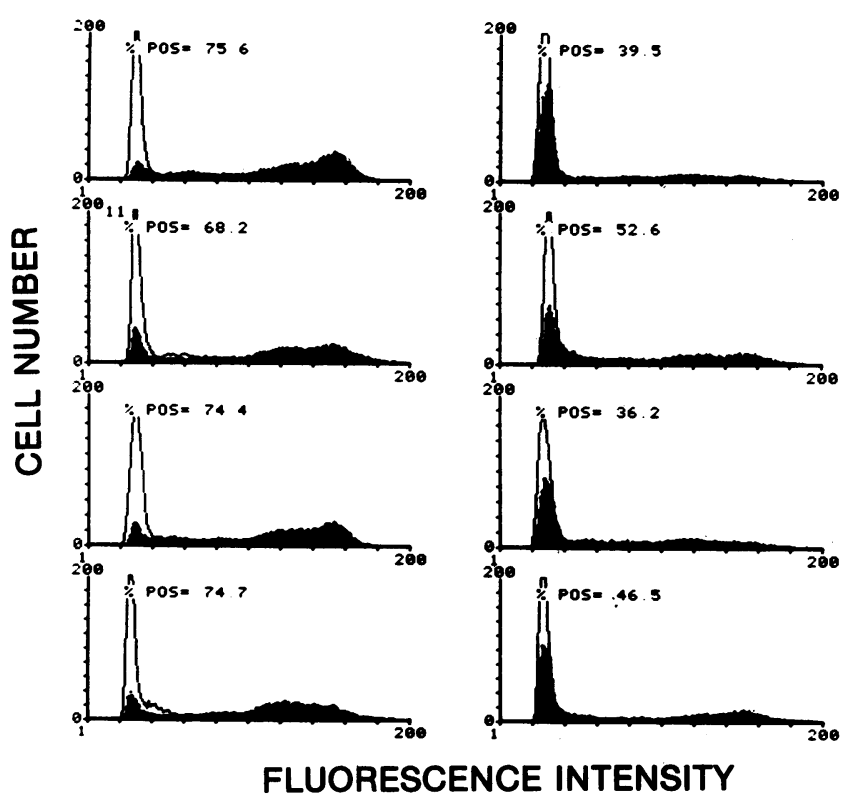

Figure 4. Cytograms of the fluorescence distribution of IL2R on lymphocytes from young and aged donors. Cells from 72-h PHA stimulated cultures of PBL were stained with a FITC labeled monoclonal antibody specific for IL2R. The percent positive cells were calculated after subtracting the fluorescent stained cells in the unstimulated cultures from those in the PHA stimulated cultures. Note that among the old donors (right panels) there are fewer numbers of IL2R positive cells in the higher intensity channels on the right of each histogram. 
provides evidence that cells from young persons have either a greater density of IL2R per unit surface area or their cells are larger with a correspondingly greater surface area able to bind more FITC-labeled antibody. After detergent solubilization, membrane-associated IL2R in the cell pellet were also quantitated by ELISA. As shown in Table III, cells from elderly donors had significantly fewer $(P<0.05)$ membrane-associated IL2R.

Soluble IL2R. Since the data indicated that cells from elderly donors have fewer cell membrane-associated IL2R, we designed experiments to determine whether there was decreased IL2R synthesis or an increased loss of IL2R from the cell membrane. No measurable levels of IL2R, either cell associated or in the culture supernatant, could be detected in unstimulated cell cultures (data not shown). The lower limit of detection in this assay is $\sim 50 \mathrm{U} / \mathrm{ml}$. As shown in Table III, culture supernatants of cells from elderly donors contained significantly less $(P<0.01)$ soluble IL2R in the culture media compared to cultures of cells from young donors. Likewise, levels of cell-associated IL2R measured by ELISA were also decreased in the cells from the aged subjects. This data suggests that there is a greater density of IL2R on the cells from young donors, since there is not a two- to threefold increase in the number of cells in the cultures from the young subjects. This question could not be definitely answered by the present experiment since the agglutinating properties of the PHA with resulting clumping of cells made it impossible to accurately determine the total number of cells in a 72-h PHA-stimulated culture. However, the finding that there is greater expression of IL2R on the cells from young donors agrees with the data obtained using the fluorescent anti-IL2R on the flow cytometer.

$I L 2$ and IL2R $m R N A$. The decreased IL2 secretion and cell membrane expression of IL2R by cells from elderly donors after PHA stimulation could be due to decreased protein synthesis or could reflect an increase in IL2R turnover rate or a difference in the distribution of receptors already present in the cell. To examine the possibility that the decreased IL2 secretion and IL2R expression reflected decreased genetic expression, cytoplasmic RNA from 6 (for IL2) and $14 \mathrm{~h}$ (for IL2R) PHA stimulated PBL of young and old donors was analyzed for IL2- and IL2R-specific mRNAs using Northern blot analysis. Cultures were harvested after 6 and $14 \mathrm{~h}$ of PHA stimulation because preliminary experiments as well as previous reports (26) demonstrated maximal accumulation of IL2 and IL2R mRNAs at these respective times. Equal quantities of total RNA (ranging from 10 to $20 \mu \mathrm{g} /$ lane for different experiments) from cells from young and old donors were

Table III. PHA-stimulated PBL Express Less IL2R

\begin{tabular}{lcl}
\hline & Membrane IL2R & \multicolumn{1}{c}{ Soluble IL2R } \\
\hline & $U / m l$ & $U / m l$ \\
Young & $4,299 \pm 915^{*}$ & $4,397 \pm 1,093$ \\
Old & $1,618 \pm 643$ & $1,545 \pm 290$
\end{tabular}

* (Mean \pm SEM, $n=13$ for young and 15 for old).

Units of IL2R were determined by ELISA and compared to a standard reference supernatant from a PHA-stimulated human PBL preparation arbitrarily defined as $1,000 \mathrm{U} / \mathrm{ml}$. loaded onto the agarose gels. The amount of RNA on the gel was verified by probing the blots with an actin CDNA, and additionally, in some experiments with a poly $(\mathrm{T}) \mathrm{cDNA}$. The levels of mRNA for both IL2 and IL2R were consistently less in RNA preparations from the cells from elderly donors as compared with the young donors. A typical Northern blot pattern comparing IL2 and actin mRNA expression in RNA preparations from three young and five old donors is shown in Fig. 5. While relatively minor differences in the expression of actin were seen from one lane to the next, marked differences in the expression of IL2 mRNA were observed. Fig. 6 shows the results of the densitometric analysis of the IL2 (top) and IL2R (bottom) mRNA bands obtained from Northern blot analysis of RNA from 13 young and 17 old donors. The area under the curve for IL2 mRNA was $1,852 \pm 412$ (mean \pm SEM) for the samples from young subjects and $685 \pm 116$ for the samples from the elderly group $(P<0.01)$. The amount of IL2R mRNA from samples from the elderly group $(3,022 \pm 298)$ was also less than that seen with samples from the young group $(4,860 \pm 698 ; P<0.01)$. Unstimulated cells from either young or old donors did not produce detectable mRNA bands when probed for either IL2 or IL2R.

\section{Discussion}

Several observations form the basis for hypotheses to explain the relative inability of lymphoid cells from aged donors to

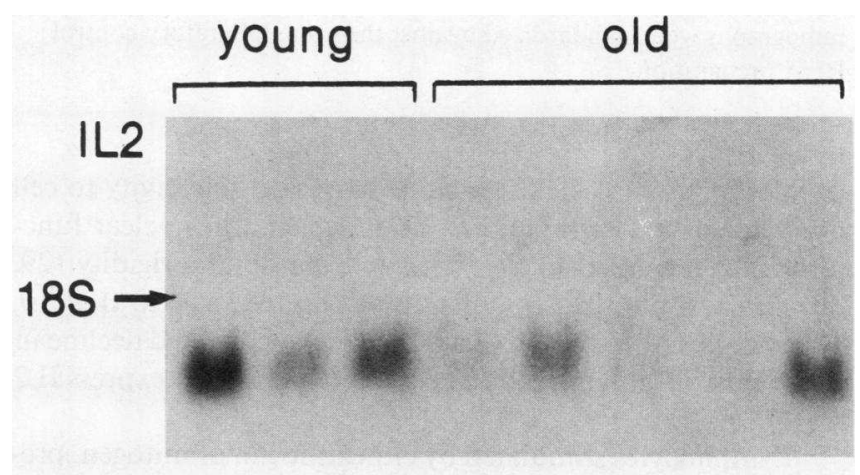

ACTIN

Figure 5. Northern blot analysis of IL2 mRNA. Total cellular mRNA from $6 \mathrm{~h}$ PHA-stimulated PBL was extracted in the presence of $4 \mathrm{M}$ guanidinium isothiocynate and then separated by centrifugation in a Beckman SW 50.1 rotor at 38,000 rpm for $18-22 \mathrm{~h}$ at $25^{\circ} \mathrm{C}$. Following electrophoresis on a $1 \%$ formaldehyde denaturing gel and capillary transfer to a nylon membrane, the blots were hybridized with a random primer ${ }^{32} \mathrm{P}$-labeled cDNA probe specific for human IL2. The amount of RNA loaded in each lane was verified by stripping the ${ }^{32} \mathrm{P}$-labeled IL2 probe from the membrane with repeated hot $0.01 \times$ SSC and $0.01 \%$ SDS treatments and hybridizing with a ${ }^{32} \mathrm{P}$-labeled actin cDNA. Two autoradiographs are shown here. Young donors $(<40 \mathrm{yr})$ are in lanes $1-3$ and old $(>60 \mathrm{yr})$ donors in lanes 4-8. 


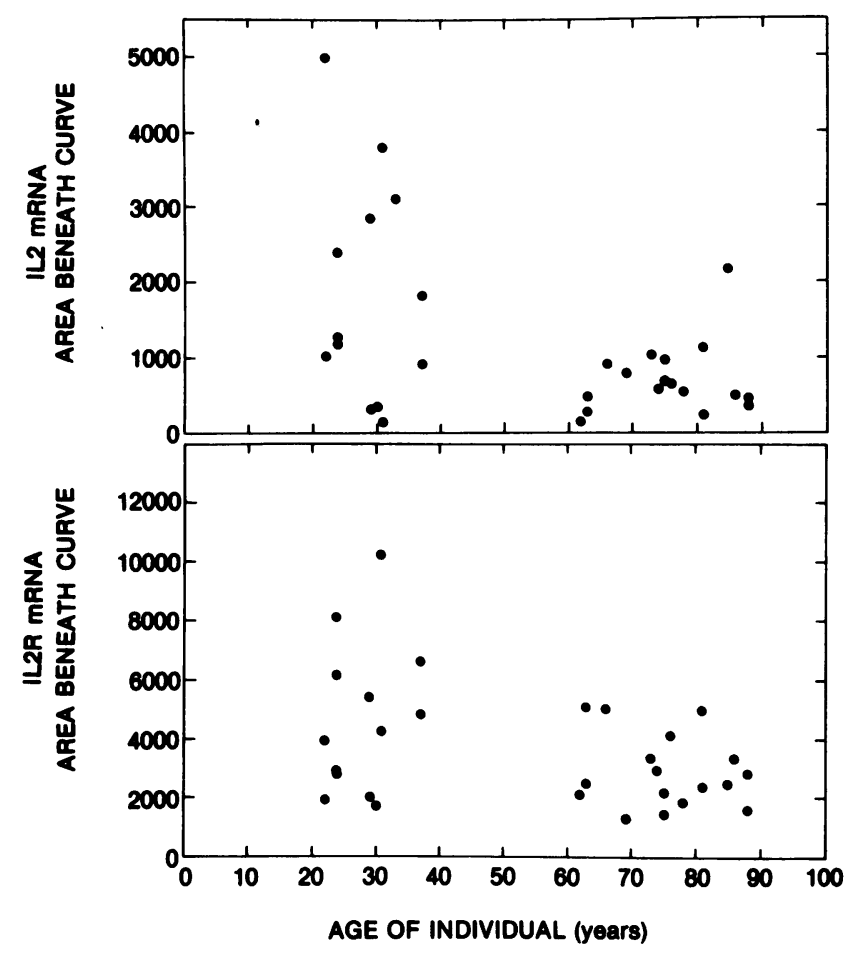

Figure 6. Relationship of IL2 and IL2R mRNA to age of donor. A scanning densitometer was used to quantitatively compare the autoradiographs of the ${ }^{32} \mathrm{P}$ labeled IL2 and IL2R mRNA blots. All autoradiographs were standardized against the same laboratory control RNA preparation.

proliferate in vitro. These include increased sensitivity to cell cycle arrest by $\left[{ }^{3} \mathrm{H}\right]$ thymidine (27), defect(s) in nuclear function (28), increased nuclear and cell membrane rigidity (29, 30 ) and a diminished production of and response to IL2 (10, $11,31)$. Recent studies have described an age-related decline in the ability of rat lymphocytes from old animals to express IL2 mRNA (32).

Lymphocytes stimulated by either antigen or mitogen, progress through a cell cycle after receiving an initial signal generated by the binding of IL 2 to its specific high affinity receptor on the cell surface (3). This binding is crucial in determining the proportion of cells that enter the proliferative phase of the cell cycle (33). Therefore, a defect in IL2 secretion or high affinity IL2R expression would tend to lead to a decrease in a proliferative response. In the present report this process was studied further and IL2 secretion, membrane IL2R expression, and mRNA levels for both IL2 and IL2R were quantitated. The results demonstrated that in PHA-stimulated cultures of PBL from old individuals there was: $(a)$ decreased IL2 secretion, $(b)$ decreased percentage of IL2R positive cells, $(c)$ a diminished IL2R density per cell, and $(d)$ a decrease in both IL2 and IL2R specific mRNA expression.

Activated $\mathrm{T}$ cells are known to express both low and high affinity IL2R (33). Recent studies indicate that the high affinity IL2R is composed of two protein subunits, both of which can bind IL2 but with different affinity and kinetics (34-36). One subunit $(\beta)$ is a $70-75-\mathrm{kD}$ glycoprotein (p70) that binds IL2 with an intermediate affinity $(34,37-39)$. When this protein noncovalently joins a 55-kD glycoprotein (p55) $\alpha$-subunit (also known as the low affinity receptor or Tac protein), a high affinity IL2R is formed. Until recently, it was thought that only the high affinity IL2R was internalized and capable of transducing the IL2 signal. However, several laboratories, using either cultured cell lines or peripheral blood mononuclear cells, have demonstrated that IL2 binds to the p70 protein and can be internalized with kinetics similar to that of the high affinity IL2R $(34,38-41)$. These experiments, along with the observation that IL2 bound only to the p55 subunit is not internalized, strongly suggest that the p70 protein is the essential component for the internalization of the IL2-IL2R ligand. The binding of IL2 to the 70-75-kD protein on large granular lymphocytes is responsible for the initial augmentation of NK and early LAK cell activity $(41,42)$.

Lectin-activated normal human T cells express $900-3000$ high affinity IL2R per cell. This number represents $<10 \%$ of the total number of IL2R on activated T cells (36). All antiIL2R monoclonal antibodies available at the present time do not distinguish between the low and high affinity forms of the IL2R. Conversely, anti-IL2R antibodies do not react with the $70-75-k D$ subunit alone $(38,39)$. Since the lower limit of detection for a fluorescent signal of a commercial flow cytometer is $\sim 2,000$ FITC equivalent molecules per cell, and the generally accepted ratio of low to high affinity IL2R is 10:1, most of the membrane-associated IL2R detected by anti-IL2R monoclonal antibody and flow cytometry is of the low affinity type. Furthermore, the IL2R cDNA clone is homologous for the p55 protein subunit gene $(21,37)$. The decreased IL2R synthesis and cell membrane IL2R expression, as well as the diminished IL2R mRNA levels detected in the present experiments, thus are indicative of defects in the synthesis or expression of the 55-kD subunit of the IL2R. Genetic control of IL2R expression is at present poorly characterized (36). The discovery that the receptor is composed of at least two protein subunits means that at least two genes, and possibly other posttranslational modifications are required for the expression of the high affinity IL2R. It is known that gene expression for IL2 and IL2R can be altered by an adherent cell population probably through a soluble mediator (26).

While incomplete, recent experimental results have yielded a general understanding of the structure of the high affinity IL2R and have produced a hypothetical two step model of T cell activation $(41,43)$. In this model resting $T$ cells are initially primed by the interaction of IL2 with the p70 protein. The binding of IL 2 to the $\beta$ subunit (IL2R $\beta$ ) results in cell activation and the induction of several $\mathrm{T}$ cell activating genes including $c-m y c, c-m y b$, and Tac. The production and presence on the cell surface of the p55 Tac protein (IL2R $\alpha$ ) results in the assembly of the p70 and p55 subunits to form the high affinity IL2R. The high affinity IL2R is then internalized where the IL2 signal is transduced leading to cell proliferation. Unactivated T cells express $\sim 600$ p70 molecules per cell, but few if any p55 molecules. This has led to the suggestion that the total number of high affinity IL2R expressed during $T$ cell activation is directly related to the availability of the p70 protein (41, 43). Data indicate that the synthesis of the p55 subunit is induced after the binding of IL2 to the p70 protein (43). Our data do not allow us to discriminate between a decreased amount or functional impairment of the $70-75-\mathrm{kD}$ protein that could lead to a defect in the induction of the $\mathrm{p} 55$ protein as was observed in cells from elderly donors in the present experiments. Additional studies employing ${ }^{125} \mathrm{I}-\mathrm{IL} 2$ to study the low, intermediate and high affinity IL2R may be useful to 
answer this question. Definite conclusions will await the development of antibodies and cDNAs to the p70 subunit.

Although it is clearly established that IL2 is essential for the proliferation of activated $\mathrm{T}$ lymphocytes, little is known regarding the mechanisms responsible for the downregulation of the effects of IL2. It has been demonstrated that mitogen-activated $T$ cells release soluble IL2R, and that under specific experimental conditions the soluble IL2R can bind IL2 $(4,6)$. This has led to the suggestion that soluble IL2R downregulates the effects of IL2 $(44,45)$. Since the activity of IL2 is dependent upon binding to IL2R (33), the decreased representation of IL2R on cells from aged donors, as well as old animals (46), may directly influence the level of a resulting proliferative response. Even though IL2 modulates the expression of the IL2R, the decreased percentage of IL2R+ cells from elderly donors cannot be due entirely to diminished IL2 synthesis. This can be seen when exogenous IL2 is added to cell cultures and there is no restoration of the percent IL $2 R^{+}$cells or the proliferative ability of the cells from old donors to levels seen with cells from young donors (47). These findings support the concept that IL2 and IL $2 \mathrm{R}^{+}$cells are in a critical equilibrium, whereby IL 2 regulates IL2R and the activation process leads to IL2 synthesis $(3,33)$. There is a major problem in trying to quantitate IL2R and IL2 binding in populations of lymphocytes from young and old donors. The problem relates to the consideration that one of the principal differences between those two populations is the number of cells that can be activated. Once the $\mathrm{T}$ cells from young or old animals or humans are activated, they perform virtually identically. The differences in responses are due to a selection process in which a smaller portion of the resting $\mathrm{T}$ cells from old donors, as compared to cells from young donors, are activated. Therefore any study examining IL2R on mitogen activated cells from young and old would be examining a similar selected cell subpopulation. ${ }^{125}$ I-IL2 binding assays are not be sensitive enough to quantify the IL2R on resting T cells. Assaying IL2R on the mitogen activated cells after 48-72 h would only deal with a "normal" responsive subpopulation regardless of the age of the donor. Additional studies employing monoclonal antibodies and cDNAs to the p70 molecule should lead to an increased understanding of the age-related defect in $\mathrm{T}$ cell proliferation.

\section{Acknowledgments}

We thank Eleanor Wielechowski for excellent secretarial assistance and Charlotte Adler for preparing the figures.

This work was supported in part by the MacArthur Foundation Research Program on Successful Aging.

\section{References}

1. Smith, K. A. 1984. Interleukin 2. Annu. Rev. Immunol. 2:319333.

2. Meuer, S. C., R. E. Hussey, D. A. Cantrell, J. D. Hogdon, S. F. Schlossman, K. A. Smith, and E. L. Reinherz. 1984. Triggering of the $\mathrm{T} 3-\mathrm{Ti}$ antigen receptor complex results in clonal $\mathrm{T}$ cell proliferation through an interleukin 2 dependent autocrine pathway. Proc. Natl. Acad. Sci. USA. 81:1509-1513.

3. Cantrell, D. A., and K. A. Smith. 1984. The interleukin T-cell system: a new cell growth model. Science (Wash. DC). 224:1312-1316.

4. Rubin, L. A., C. C. Kurman, M. E. Fritz, W. F. Biddison, B.
Boutin, R. Yarchoan, and D. L. Nelson. 1985. Soluble interleukin 2 receptors are released from activated human lymphoid cells in vitro. $J$. Immunol. 135:3172-3177.

5. Diamantstein, T., H. Osawa, A. Mouzaki, and O. JosimovicAlasevic. 1986. Regulation of interleukin 2 receptor expression and receptor release. Mol. Immunol. 23:1165-1172.

6. Rubin, L. A., G. Jay, and D. L. Nelson. 1986. The released interleukin 2 receptor binds interleukin 2 efficiently. J. Immunol. 137:3841-3844.

7. Nagel, J. E. 1983. Immunology of aging. Rev. Biol. Res. Aging. $1: 103-162$.

8. Gottesman, S. R. C. 1987. Changes in T cell mediated immunity with age-an update. Rev. Biol. Res. Aging. 3:95-127.

9. Thoman, M. L., and W. O. Weigle. 1985. Reconstitution of in vivo cell-mediated lympholysis responses in aged mice by interleukin 2. J. Immunol. 134:949-952.

10. Gillis, S., R. Kozak, M. Durante, and M. E. Weksler. 1981. Immunological studies of aging. Decreased production of and response to $\mathrm{T}$ cell growth factor by lymphocytes from aged humans. J. Clin. Invest. 67:937-942.

11. Gilman, S. C., J. S. Rosenberg, and J. D. Feldman. 1982. T lymphocytes from young and aged rats. II. Functional defects and the role of interleukin-2. J. Immunol. 128:644-650.

12. Rabinowich, H., Y. Goses, T. Reshef, and A. Klajman. 1985. Interleukin-2 production and activity in aged humans. Mech. Ageing Dev. 32:213-226.

13. Arya, S. K., F. Wong-Staal, and R. C. Gallo. 1984. Dexamethasone mediated inhibition of human $\mathrm{T}$ cell growth factor and gamma interferon messenger RNA. J. Immunol. 133:273-276.

14. Krönke, M., W. J. Leonard, J. M. Depper, and W. C. Greene. 1985. Sequential expression of genes involved in human $T$ lymphocyte growth and differentiation. J. Exp. Med. 161:1593-1598.

15. Nagel, J. E., F. J. Chrest, and W. H. Adler. 1982. Mitogenic activity of 12-0-tetradecanoyl phorbol-13-acetate on peripheral blood lymphocytes from young and aged adults. Clin. Exp. Immunol. 49:217-224.

16. Gillis, S., M. M. Ferm, W. Ou, and K. A. Smith. 1978. T-cell growth factor: parameters of production and a quantative microassay for activity. J. Immunol. 120:2027-2032.

17. Nagel, J. E., F. J. Chrest, and W. H. Adler. 1981. Enumeration of $\mathrm{T}$ lymphocyte subsets by monoclonal antibodies in young and aged humans. J. Immunol. 127:2086-2088.

18. Nagel, J. E., F. J. Chrest, R. S. Pyle, and W. H. Adler. 1983. Monoclonal antibody analysis of $\mathrm{T}$ lymphocyte subsets in young and aged adults. Immunol. Commun. 12:223-237.

19. Chirgwin, J. M., A. E. Przybyla, R. J. McDonald, and W. J. Rutter. 1979. Isolation of biologically active ribonucleic acid from sources enriched in ribonuclease. Biochemistry. 18:5294-5299.

20. Thomas, P. S. 1980. Hybridization of denatured RNA and small DNA fragments transferred to nitrocellulose. Proc. Natl. Acad. Sci. USA. 77:5201-5205.

21. Leonard, W. J., J. M. Depper, G. R. Crabtree, S. Rudikoff, J. Pumphrey, R. J. Robb, M. Krönke, P. B. Svetlik, N. J. Peffer, T. A. Waldmann, and W. C. Greene. 1984. Molecular cloning and expression of cDNAs for the human interleukin-2 receptor. Nature (Lond.). 311:626-631.

22. Holbrook, N. J., K. A. Smith, A. J. Fornace, Jr., C. M. Comeau, R. L. Wiskocil, and G. R. Crabtree. 1984. T-cell growth factor: complete nucleotide sequence and organization of the gene in normal and malignant cells. Proc. Natl. Acad. Sci. USA. 81:1634-1638.

23. Gunning, P., P. Ponte, H. Okayama, J. Engel, H. Blau, and L. Kedes. 1983. Isolation and characterization of full-length cDNA clones for human $\alpha-, \beta$-, and $\gamma$-actin mRNAs: skeletal but not cytoplasmic actins have an amino terminal cysteine that is subsequently removed. Mol. Cell. Biol. 3:787-795.

24. Feinberg, A. P., and B. Vogelstein. 1983. Technique for radiolabelling DNA endonuclease fragments to high specific activity. Anal. Biochem. 132:6-13. 
25. Cantrell, D. A., and K. A. Smith. 1983. Transient expression of interleukin-2 receptors: consequences for T-cell growth. J. Exp. Med. 158:1895-1911.

26. Kern, J. A., J. C. Reed, R. P. Daniele, and P. C. Nowell. 1986. The role of the accessory cell in mitogen-stimulated human $T$ cell gene expression. J. Immunol. 137:764-769.

27. Staiano-Coico, L., Z. Darzynkiewicz, M. R. Melamed, and M. E. Weksler. 1984. Immunological Studies of Aging. IX. Impaired proliferation of $\mathrm{T}$ lymphocytes detected in elderly humans by flow cytometry. J. Immunol. 132:1788-1792.

28. Gutowski, J. K., J. Innes, M. E. Weksler, and S. Cohen. 1984. Induction of DNA synthesis in isolated nuclei by cytoplasmic factors. II. Normal generation of cytoplasmic stimulatory factors by lymphocytes from aged humans with depressed proliferative responses. J. Immunol. 132:559-562.

29. Hegner, D. 1980. Age-dependence of molecular and functional changes in biological membrane properties. Mech. Ageing Dev. 14:101-118.

30. Traill, K. N., K. Ratheiser, M. Dietrich, S. Sailer, J. L. Zevenbergen, and G. Wick. 1984. Lack of correlation between serum cholesterol levels, lymphocyte plasma membrane fluidity and mitogen responsiveness in young and aged chickens. Mech. Ageing Dev. 28:123-138.

31. Thoman, M. L., and W. O. Weigle. 1982. Cell-mediated immunity in aged mice: an underlying lesion in IL2 synthesis. J. Immunol. 128:2358-2361.

32. Wu, W., M. Pahlavani, H. T. Cheung, and A. Richardson. 1986. The effect of aging on the expression of interleukin 2 messenger ribonucleic acid. Cell. Immunol. 100:224-231.

33. Smith, K. A., and D. A. Cantrell. 1985. Interleukin 2 regulates its own receptors. Proc. Natl. Acad. Sci. USA. 82:864-868.

34. Robb, R. J., C. M. Rusk, J. Yodoi, and W. C. Greene. 1987. Interleukin 2 binding molecule distinct from the Tac protein: analysis of its role in formation of high-affinity receptors. Proc. Natl. Acad. Sci. USA. 84:2002-2006.

35. Dukovich, M., Y. Wano, L. Bich-Thuy, P. Katz, B. R. Cullen, J. H. Kerhl, and W. C. Greene. 1987. A second interleukin-2 binding protein that may be a component of high-affinity interleukin-2 receptors. Nature (Lond.) 327:518-522.

36. Greene, W. C. 1987. The human interleukin-2 receptor: a mo- lecular and biochemical analysis of structure and function. Fed. Proc. 35:439-450.

37. Sharon, M., R. D. Klausner, B. R. Cullen, R. Chizzonite, and W. J. Leonard. 1986. Novel interleukin-2 receptor subunit detected by cross-linking under high affinity conditions. Science (Wash. DC). 234:859-863.

38. Tsudo, M., R. W. Kozak, C. K. Goldman, and T. A. Waldman. 1986. Demonstration of a non-Tac peptide that binds interleukin 2. A potential participant in a multichain interleukin 2 receptor complex. Proc. Natl. Acad. Sci. USA. 83:9694-9698.

39. Teshigawara, K., H. Wang, K. Kato, K. A. Smith. 1987. Interleukin 2 high affinity receptor expression requires two distinct binding proteins. J. Exp. Med. 165:223-238.

40. Robb, R. J., and W. C. Greene. 1987. Internalization of interleukin 2 is mediated by the $\beta$ chain of the high-affinity interleukin 2 receptor. J. Exp. Med. 165:1201-1206.

41. Siegel, J. P., M. Sharon, P. L. Smith, and W. J. Leonard. 1987. The IL-2 receptor $\beta$ chain (p70): role in mediating signals for LAK, NK, and proliferative activities. Science (Wash. DC). 238:75-78.

42. Tsudo, M., C. K. Goldman, K. F. Bongiovanni, W. C. Chan, E. F. Winton, M. Yagita, E. A. Grimm, and T. A. Waldman. 1987. The p75 peptide is the receptor for interleukin 2 expressed on large graular lymphocytes and is responsible for the interleukin 2 activation of these cells. Proc. Natl. Acad. Sci. USA. 84:5394-5398.

43. Bich-Thuy, L., M. Dukovich, N. J. Peffer, A. S. Fauci, J. H. Kehrl, and W. C. Greene. 1987. Direct activation of human resting T cells by IL2: the role of an IL2 receptor distinct from the Tac protein. $J$. Immunol. 139:1550-1556.

44. Kumar, A., J.-L. Moreau, D. Baran, and J. Theze. 1987. Evidence for negative regulation of $\mathrm{T}$ cell growth by low affinity interleukin 2 receptors. J. Immunol. 138:1485-1493.

45. Jacques, Y., B. LeMauff, F. Boeffard, A. Godard, and J.-P. Soulillou. 1987. A soluble interleukin 2 receptor produced by a normal alloreactive human $\mathrm{T}$ cell clone binds interleukin 2 with low affinity. $J$. Immunol. 139:2308-2316.

46. Vie, H., and R. A. Miller. 1986. Decline with age, in the proportion of mouse $\mathrm{T}$ cells that express IL-2 receptors after mitogen stimulation. Mech. Ageing Dev. 33:313-322.

47. Grabstein, K., S. Dower, S. Gillis, D. Urdal, and A. Larsen. 1986. Expression of interleukin 2, interferon- $\gamma$ and the IL2 receptor by human peripheral blood lymphocytes. J. Immunol. 136:4503-4508. 